\title{
Suppression of UDP-glycosyltransferase-coding Arabidopsis thaliana UGT74E2 Gene Expression Leads to Increased Resistance to Psuedomonas syringae pv. tomato DC3000 Infection
}

\author{
Hyo Jun Park ${ }^{1}$, Chang Seob Kwon ${ }^{2}$, Joo-Yong Woo ${ }^{1}$, Gil-Je Lee ${ }^{1}$, Young Jin Kim ${ }^{1}$ and Kyung-Hee Paek ${ }^{1 *}$ \\ ${ }^{1}$ Plant Signaling Network Research Center, School of Life Sciences and Biotechnology, Korea University, Seoul 136-701, Korea \\ ${ }^{2}$ Department of Chemistry and Biology, Korea Science Academy of KAIST, Busan 614-822, Korea \\ (Received on January 4, 2011; Accepted on April 13, 2011)
}

Plants possess multiple resistance mechanisms that protect themselves against pathogen attack. To identify unknown components of the defense machinery in Arabidopsis, gene-expression changes were monitored in Arabidopsis thaliana under 18 different biotic or abiotic conditions using a DNA microarray representing approximately $25 \%$ of all Arabidopsis thaliana genes (www.genevestigator.com). Seventeen genes which are early responsive to salicylic acid (SA) treatment as well as pathogen infection were selected and their T-DNA insertion mutants were obtained from SALK institute. To elucidate the role of each gene in defense response, bacterial pathogen Pseudomonas syringae pv. tomato (Pst) DC3000 was inoculated onto individual T-DNA insertion mutants. Four mutants exhibited decreased resistance and five mutants displayed significantly enhanced resistance against Pst DC3000-infection as measured by change in symptom development as compared to wild-type plants. Among them, member of uridin diphosphate (UDP)-glycosyltransferase (UGT) was of particular interest, since a $U G T$ mutant (At1g05680) showed enhanced resistance to Pst-infection in Arabidopsis. In systemic acquired resistance (SAR) assay, this mutant showed enhanced activation of SAR. Also, the enhanced SAR correlated with increased expression of defenserelated gene, AtPR1. These results emphasize that the glycosylation of UGT74E2 is a part of the SA-mediated disease-resistance mechanism.

Keywords : Arabidopsis, Pseudomonas syringae, salicylic acid, systemic acquired resistance, UDP-gylcosyltransferase, UGT74E2

In nature, plants and pathogens keep up with developing a variety of weapons to attack each other for their successful survival during life time. Plants, as a defender, are under continuous biotic stresses derived from diverse invaders

\footnotetext{
*Corresponding author.

Phone) +82-2-3290-3440, FAX) +82-2-928-1274

E-mail)khpaek95@korea.ac.kr
}

including bacteria, fungi, viruses, and insect herbivores. Plant pathogens can generally be divided into three classes: biotrophs, necrotrophs, and hemibiotrophs according to their lifestyles. Biotrophic pathogens cause minimal damage to the host cell, although disease symptoms usually occur as a result of nutrient exhaustion. Necrotrophs, in contrast, rely upon dead host cell for reproduction and nutrient. However, many pathogens behave as both biotrophs and necrotrophs. Hemibiotrophs are biotrophic in one stage of the infection cycle and necrotrophic in another stage of invasion cycle (Glazebrook, 2005; Hancock and Husiman, 1981; Spoel et al., 2007). In response to those invaders, plants operate complex defense mechanisms at the level of molecular, cellular, and whole-plant (Beckers and Spoel, 2006; Jones and Dangl, 2006). These sophisticated defense responses commonly involve the harmonious transcriptional activation of multiple genes and the phytohormones including salicylic acid, jasmonic acid, and ethylene are involved. The specific disease resistance response often includes the activation of the hypersensitive response (HR) and development of systemic acquired resistance (SAR) (Dangl and Jones, 2001).

Salicylic acid (SA) is a well known crucial component that is associated with plant disease resistance. SA level increases in plant tissue following pathogen infection, and exogenous treatment of SA triggers both induced resistance to broad range of pathogens and the accumulation of pathogenesis-related proteins (Kunkel and Brooks, 2002). Outbreak of attack by certain pathogens generates activation of SA-dependent signaling. Plant resistance to biotrophic pathogens is normally thought to be mediated through SA signaling (Loake and Grant, 2007). In Arabidopsis thaliana, two genes, PAD4 and EDS1, are needed for activating SA accumulation in response to SA-inducing stresses (Falk et al., 1999). Previous reports indicate that the majority of SA is produced by way of SID2 which encodes isochorismate synthase (Wildermuth et al., 2001). EDS5 is also essential for production of SA against pathogen attack (Ferrari et al., 2003; Rossi et al., 1998). The experiment of transgenic 
$N a h G$, which encodes a bacterial (Pseudomonas putida) salicylate hydroxylase, reveals that SA is required for activation of defense-related genes such as pathogenesisrelated genel (PRI) and for induction of SAR (Delaney et al., 1994; Gaffney et al., 1993). When SA levels are increased, $N P R 1$, which acts downstream from $\mathrm{SA}$, is converted to active monomer and this signaling regulated the conformation of NPR1 by S-nitrosylation (Mou et al., 2003; Tada et al., 2008). Activated NPR1 then is localized to the nucleus, where it interacts with TGA transcription factor, ultimately leading to the activation of $P R 1$ (Spoel et al., 2003). Even though there are many efforts to dissect SA mechanism in plants, the complete mechanism is not fully defined yet.

Recognition of pathogen often causes a localized resistance reaction, including HR, a programmed cell death (PCD), at site of invasion. Previous report showed that this local resistance spreads to the non-infected site (Ross, 1961). SAR requires transmittance of a signal from infected tissue to the systemic leaves. At first, SA was thought to be a SAR-inducing signal because application of exogenous SA triggers defense response including expression of pathogenesis-related $(P R)$ genes, HR, and restriction of pathogen movement (Dempsey et al., 1999). However, the grafting experiment in tobacco showed that transgenic root stock, although unable to accumulate SA, was completely capable of delivering a signal that rendered non-transgenic scions resistant to secondary pathogen infection (Vernooij et al., 1994). Moreover, previous studies suggested that signaling might occur through the conversion of SA to the volatile compound methyl salicylate in tobacco (Park et al., 2007; Shulaev et al., 1997). These results indicate that SA itself is not a mobile signal for SAR.

In plant biological processes, modification of phytohormones, including salicylic acid, jasmonic acid, and ethylene, by glycosylation, methylation, and amino acid conjugation, is regarded as an integral control process.

It was known that most pathogen-induced SA is glycosylated by uridine diphosphate (UDP)-glycosyltransfersae (UGT) to form non-toxic SA 2-O- $\beta$-D-glucoside (SAG). Recent studies suggest that methylation and amino acid conjugation as well as glycosylation of SA play a specific role in plant defense (Dean et al., 2005; Loake and Grant, 2007). UGTs convey the transfer of glycosyl residues from activated nucleotide sugars to a wide range of acceptor molecules such as secondary metabolites including SA and phytoalexins. Secondary metabolites accomplish multiple functions in plants, including lignifications, UV protection, herbivore protection, and disease resistance. It is supposed that UGTs are involved in bioactivity, solubility and transport of such secondary metabolites within the cell and throughout the plant. This protein constitutes a large gene family in higher plants. It was reported that there are over 120 and 165 UGT genes in Arabidopsis thaliana and Medicago truncatula, respectively. The UGTs are classified by the presence of a carboxy-terminal 42 amino acid consensus sequence that is thought to be involved in binding of the protein to the UDP part of the sugar nucleotide. Recently, the PSPG-box, that is a signature sequence of glycosyltransferase, was found in Dorotheanthus bellidiformis. This consensus sequence also can be identified in ORFs from animal, plant, yeast, and bacterial genomes. A phylogenetic analysis reveals the presence of 14 distinct groups (A to N) of UGTs in Arabidopsis. Among these family members, at first only group D was reported to be associated with disease resistance against some pathogens in Arabidopsis. A UGT group D encompasses 13 members in Arabidopsis. And it was reported that expression of UGT73B3 and $U G T 73 B 5$ genes is necessary for resistance to Pseudomonas syringae pv. tomato in Arabidopsis. In recent years, a number of UGTs were characterized in Arabidopsis including UGT73C5, UGT73C6, UGT73B2, and so forth. And also, down-regulation of tobacco glycosyltransferase gene (TOGTI) showed decreased resistance to Tobacco mosaic virus (TMV). (Chong et al., 2002; Gachon et al., 2005; LangloisMeurinne et al., 2005; Ma et al., 2007; Ross et al., 2001). Despite of these efforts for connecting UGTs in plant defense mechanism, the exact role of UGTs remains unclear.

In this study, we performed a reverse genetic screening for finding SA- and Pst- inducible genes, and functional analysis of one of Arabidopsis UGT gene family members, UGT74E2. UGT74E2 was obtained throughout T-DNA insertion mutant screening of bacterial growth assay by using Arabidopsis-Pseudomonas interaction as a model system during the process of local- and systemic-resistance. Our finding suggested that UGT74E2 plays an important role in local and systemic resistance in Arabidopsis.

\section{Materials and Methods}

Plant materials and treatments. Arabidopsis thaliana ecotype Columbia-0, 21 different kinds of T-DNA insertion mutants, npr l-mutants, and NahG transgenic plants were grown in pot containing soil. The plants were grown in growth room with $16 \mathrm{~h}$ light and $8 \mathrm{~h}$ dark (long-day condition) at $23-25^{\circ} \mathrm{C}$ for $4-5$ weeks before carrying out experiments. For sterile culture, seeds were surface-sterilized in $70 \%$ ethanol for $3 \mathrm{~min}$, treated with $25 \%$ commercial clorax containing $0.05 \%$ Tween 20 (ICI Americas Inc., USA) for $5 \mathrm{~min}$, and rinsed five times with sterile water. Then, the seeds were planted onto MS medium and grown in growth chamber for 3-4 weeks before bacterial inoculation. The pots and the plates were stored at $4{ }^{\circ} \mathrm{C}$ for $72 \mathrm{~h}$ to ensure uniform germination. 
Table 1. Arabidopsis gene-specific primer pairs for mutant genotyping

\begin{tabular}{|c|c|c|}
\hline AGI & Polymorphism & Sequence \\
\hline At5g11920 & SALK_152299 & $\begin{array}{l}\text { Forward: AAGTCACAGTTGTTGCCGAAC } \\
\text { Reverse: TGGTTTTACTGCATTTACCTCAAG }\end{array}$ \\
\hline Atlg29020 & SALK_062045 & $\begin{array}{l}\text { Forward: GGTTTCTTTGGCGGAATTATC } \\
\text { Reverse: CAGAATCAAATAAAAAGAGCGTTTC }\end{array}$ \\
\hline At5g45070 & SALK_143717 & $\begin{array}{l}\text { Forward: TATGGTTCGCGTTTGCAG } \\
\text { Reverse: TTCATGAACTCTCTTTCGTTCC }\end{array}$ \\
\hline Atlg50090 & SALK_070362 & $\begin{array}{l}\text { Forward: CAACTTTGAGGTTCAAGCCTG } \\
\text { Reverse: ATGCGAATGTAAAATGGGATG }\end{array}$ \\
\hline At4g35180 & SALK_027033 & $\begin{array}{l}\text { Forward: TTGACCAAAACATCCGAAGAG } \\
\text { Reverse: AAACCAAGAAGCATTGCACTG }\end{array}$ \\
\hline At4g10500 & SALK_059907 & $\begin{array}{l}\text { Forward: ATTCCATCCCTCTGATCGATC } \\
\text { Reverse: ATCACTGCATCTGTTGAAGGG }\end{array}$ \\
\hline At3g23190 & SALK_123883 & $\begin{array}{l}\text { Forward: CTACAAAACGTGAGAATCCCG } \\
\text { Reverse: CAACACAAATGATCGGTTGTG }\end{array}$ \\
\hline At3g56400 & SALK_025198 & $\begin{array}{l}\text { Forward: GGTGTTACACGTGTGGTTTCC } \\
\text { Reverse: CAAACCACACCAAGAGGAAAG }\end{array}$ \\
\hline Atlg17170 & SALK_034472 & $\begin{array}{l}\text { Forward: CAGTGGCCTAAGCAACTAACG } \\
\text { Reverse: TAACTCCTTGGCTGCTTCTTG }\end{array}$ \\
\hline At $\lg 44050$ & SALK_011264 & $\begin{array}{l}\text { Forward: GAACATTTTATCTTCGCCGTG } \\
\text { Reverse: CAGACGTTTGTAAGCTCCCTG }\end{array}$ \\
\hline At $\lg 15640$ & SALK_001121 & $\begin{array}{l}\text { Forward: AAAATTATCCAAAATAACCTAGATATCC } \\
\text { Reverse: CAGCCACCGGTATAACAGATG }\end{array}$ \\
\hline At5g59490 & SALK_080547 & $\begin{array}{l}\text { Forward: GAGGGACTTTTAGGAATCTTCTTG } \\
\text { Reverse: GCTCTCACAAGACTTGGCATC }\end{array}$ \\
\hline At $2 g 40750$ & SALK_095417 & $\begin{array}{l}\text { Forward: ACTTTTCCGGCGTTTTTAATG } \\
\text { Reverse: TGGATTTCGTGTTGTTACTATTCG }\end{array}$ \\
\hline At2g04050 & SALK_142350 & $\begin{array}{l}\text { Forward: GAGAGAAAGGAGTCCACGACC } \\
\text { Reverse: AAAATACTGAACCCGGAAACG }\end{array}$ \\
\hline Atlg05680 & SALK_016116 & $\begin{array}{l}\text { Forward: TCTTGGAAACCATTGGAGATG } \\
\text { Reverse: TAAGCTGGAGTCCTCAGCTTG }\end{array}$ \\
\hline At3g53480 & SALK_035704 & $\begin{array}{l}\text { Forward: TTTGTTAAAGGCCTTGTCTGG } \\
\text { Reverse: GCGAAACAAGTACAGTAGCGC }\end{array}$ \\
\hline At $2 g 14560$ & SALK_039201 & $\begin{array}{l}\text { Forward: GCACAACAATAACGAGCATACTC } \\
\text { Reverse: TTTGATACATCTGGAATAAACATGTG }\end{array}$ \\
\hline
\end{tabular}

For hormone treatments, a final concentration of $1 \mathrm{mM}$ was used for SA, $50 \mu \mathrm{M}$ for methyl jasmonate, and $20 \mu \mathrm{M}$ for 2,4-Dichlorophenoxyacetic acid (2,4-D). Each hormone was dissolved in water and applied to 3-week-old early seedlings grown in MS medium. The seeds of T-DNA insertion mutants were obtained from ABRC (Arabidopsis Biological Resource Center, USA). The information of SALK-line mutants and specific primer sequence for genotyping used in this study is provided in Table 1.

Mutant genotyping. Genomic DNA was isolated from 4week-old Arabidopsis leaves by using CTAB method as following: Two or three Arabidopsis leaves were collected into $1.5 \mathrm{ml}$ eppendorf tube, and the juice was released with pestle at room temperature $(\mathrm{R} / \mathrm{T})$. Then $400 \mu \mathrm{l}$ of $\mathrm{CTAB}$ buffer (3\% CTAB (ICI Americas Inc., USA), $1.4 \mathrm{M} \mathrm{NaCl}$,
$20 \mathrm{mM}$ EDTA, $100 \mathrm{mM}$ Tris-HCl, and $200 \mathrm{mM} \beta$-Mercaptoethanol (Sigma-Aldrich, USA)) was added to the tube, and the tissue was completely ground with pestle. The mixture was incubated at $65^{\circ} \mathrm{C}$ incubator for $30 \mathrm{~min}$. Four hundred microliters of chloroform was added to the mixture, and then the suspension was centrifuged at $14,000 \mathrm{rpm}$ for 10 min. The supernatant was transferred into fresh tube, and $250 \mu \mathrm{l}$ of isopropanol was added. The mixture was incubated at $\mathrm{R} / \mathrm{T}$ for $30 \mathrm{~min}$ to overnight. The mixture was centrifuged for $10 \mathrm{~min}$ at $\mathrm{R} / \mathrm{T}$. Then the pellet was ethanol precipitated. After the supernatant was discarded, the DNA was gently dissolved in TE buffer, $\mathrm{pH}$ 8.0.

The SALK homozygote was confirmed by PCR using a T-DNA-specific (LBa1 5'-TGGTTCACGTAGTGGGCCATCG-3') and an Arabidopsis thaliana gene-specific primer pair for the presence of the insertion site (Table 1). 
Pathogens and inoculation procedures. The bacterial leaf pathogen Pseudomonas syringae pv tomato DC3000 (Pst DC3000), Pst DC3000 containing an AvrRpml (Pst DC3000 avrRpm1), and fungal pathogens (Alternaria brassicicola and Botrytis cinerea) were used in this study.

Pst DC3000 was cultured overnight in King's B medium containing $50 \mu \mathrm{g} \mathrm{mL}^{-1}$ rifampicin. Pst DC3000 avrRpm1 was cultured overnight in King's B medium containing 50 $\mu \mathrm{g} \mathrm{mL}{ }^{-1}$ rifampicin and $50 \mu \mathrm{g} \mathrm{mL} \mathrm{m}^{-1}$ kanamycin at $28^{\circ} \mathrm{C}$ with vigorous shaking. Prior to inoculation, bacterial cells were collected by centrifugation and were resuspended in $10 \mathrm{mM} \mathrm{MgCl}_{2}$ solution. Leaves of 4-week-old Arabidopsis plants were inoculated by dipping, syringe infiltration, or vacuum infiltration of bacterial suspension cultures.

For the pathogenicity assay, Arabidopsis plants were dipped in $1 \times 10^{7}$ cfu of Pst DC3000 in $10 \mathrm{mM} \mathrm{MgCl}_{2}$. For the local resistance assay, leaves of 4-week-old Arabidopsis were infiltrated with $5 \times 10^{4}$ cfu of Pst DC3000 using vacuum pump. The infected plants were incubated in controlled chamber to observe the symptom development. Infected leaves were harvested at $0,1,3$, and 5 days after inoculation. Bacterial growth experiments were repeated more than three times for each result.

A. brassicicola and $B$. cinerea were cultured on potato dextrose agar (PDA) medium at $28^{\circ} \mathrm{C}$. Conidia of $A$. brassicicola and $B$. cinerea were collected from 12-day-old cultures in PDA $\left(24 \mathrm{~g} \mathrm{~L}^{-1}\right)$, and then $10 \mu$ suspension of $5 \times$ $10^{4}$ spores $\mathrm{mL}^{-1}$ in PD broth was inoculated on leaves of individual 4-week-old plants. After five days, lesion-size of A. brassicicola on the leaves was measured, and susceptibility to $B$. cinerea was evaluated by microscopic observation of the diameter of the symptom. All inoculated plants were covered with a transparent film to maintain humidity and then put in a growth chamber at $22^{\circ} \mathrm{C}$ under $16 \mathrm{~h}$ light.

The symptom of bacterial and fungal blight of Arabidopsis leaf are normally leaf wilting and discoloration, leaf drop, a little bit stunting and finally wilting and death. Disease incidence was quantified by determining the disease severity after bacterial inoculation. Disease severity ratings were expressed on the basis of symptom severity and area of chlorosis on each leaf: 1 , no symptom or chlorosis on the leaf; $2,<30 \%$ of the leaf area covered with chlorosis and no cell death observed; $3,<60 \%$ of the leaf area covered with chlorosis; $4,>60 \%$ of the leaf area covered with chlorosis and cell death observed; 5 , leaves of heavy cell death with chlorosis and leaf collapse

Systemic acquired resistance assay. SAR was observed by comparing growth of virulent Pst DC3000 in upper parts of plants after SAR induction. Plants were either SARinduced by inoculation in two or three leaves with avirulent
Pst DC3000 avrRpm1 $\left(10^{6} \mathrm{cfu} / \mathrm{ml}\right)$ or mock-inoculated with $10 \mathrm{mM} \mathrm{MgCl}_{2}$ using syringe infiltration method. And three days later, the plants were challenged by inoculation of upper leaves with virulent Pst DC3000 strain $\left(5 \times 10^{4}\right.$ cfu/ml).

Extraction of total RNA. Approximately three to four Arabidopsis leaves were ground in liquid nitrogen to fine powder in pre-chilled $2 \mathrm{ml}$ centrifuge tube (Sarstedt, Germany). The powder was transferred into $400 \mu$ of RNA extraction buffer (0.2 M Tris-HCl, $\mathrm{pH} 8.0,0.4 \mathrm{M} \mathrm{LiCl}_{2}, 25$ mM EDTA, pH 8.0, and 1\% SDS), and mixed well. Four hundred microliters of water-saturated phenol were added to the tube. The tubes were centrifuged at $14,000 \mathrm{~g}$ for 15 $\min$ at $4{ }^{\circ} \mathrm{C}$. The supernatant was transferred into new tubes and $400 \mu \mathrm{l}$ of chloroform were added. The tubes were centrifuged at $13,000 \mathrm{~g}$ for $15 \mathrm{~min}$ at $4{ }^{\circ} \mathrm{C}$. Then the supernatant was ethanol precipitated. The pellet was washed with DEPC-treated $70 \%$ ethanol, and dissolved in $4 \mathrm{M} \mathrm{LiCl}_{2}$. After re-precipitation, the pellet was dissolved in DEPCtreated water.

RT-PCR analysis. The cDNA was synthesized by using 3 $\mu \mathrm{g}$ of total RNA, oligo (dT) primer and superscript reverse transcriptase (Promega, USA). Semiquantitative RT-PCR was performed as described by Liu et al. (2002). The genespecific primers for UGT74E2, AtPR1, AtPR2, AtPR3, AtPR4, AtPR5, NPR1, TGA, IAA1, PDF1.2, and AtActin7 are listed in the Table 2. The AtActin 7 gene was used as an internal control for RNA quantity in RT-PCR analysis. The intensities of RT-PCR-amplified fragments were analyzed and quantified using Quantity One (Ver. 4.3, Bio-Rad, USA) and Multi Gauge (Ver. 3.0, Fujifilm, Japan).

Real-Time PCR analysis. Total RNA ( $3 \mu \mathrm{g})$ was converted into cDNA with the superscript reverse transcriptase (Promega, USA) using oligo (dT), yielding $20 \mu \mathrm{L}$ of cDNA solution. Quantitative RT-PCR was performed using the Lightcycler 480 system (Roche). The amplification reaction mixture contained $2 \mu \mathrm{L}$ of 2 -fold diluted cDNA template, 2 $\mu \mathrm{L}$ of primer solution (containing $10 \mathrm{mM}$ [10 pmol/mL] of each forward and reverse primer), $8 \mu \mathrm{L}$ of SYBR Green PCR Master Mix (Takara, Japan). The primer pairs used in the real-time PCR are listed in the Supplemental Table 2. Thermal cycling conditions consisted of $10 \mathrm{~min}$ at $95^{\circ} \mathrm{C}$, and 40 cycles of $10 \mathrm{sec}$ at $95^{\circ} \mathrm{C}, 15 \mathrm{sec}$ at $56^{\circ} \mathrm{C}, 15 \mathrm{sec}$ at $72^{\circ} \mathrm{C}$. Transcript levels were normalized to the expression of AtActin 7 measured in the same samples.

Isolation and sequence alignment of $U G T 74 E 2$ cDNA fragments. To isolate $U G T 74 E 2$ cDNA fragment, RNA was extracted from Pst DC3000-inoculated Arabidopsis 
Table 2. Arabidopsis gene-specific primer pairs for PCR analysis

\begin{tabular}{c} 
AGI \\
\hline Atlg05680 Forward: AGAAAGAATGCTGAGAAATGGAA \\
(UGT74E2) Reverse: TGGACTTGCAAAAGACGATG \\
At2g14610 Forward: CGGAGCTACGCAGAACAACT \\
(AtPR1) Reverse: CGTTCACATAATTCCCACGA \\
At3g57260 Forward: TCCTTAGAGACTTGTGGGCTTT \\
(AtPR2) Reverse: CCTATAGGCCCATGCTATTTTT \\
At3g12500 Forward: CTTCGTTAACGGCCTCCTC \\
(AtPR3) Reverse: GGGAAATAAAATCGCAACATAAA \\
At3g04720 Forward: CCATTGATCGCGTTTGATATT \\
(AtPR4) Reverse: CGAAACATATATCCCTCGACAA \\
At1g75040 Forward: TCGGGTTTAATTATCTCTCACG \\
(AtPR5) Reverse: TCCGTAGATCAATCATTTTGTTT \\
At5g09810 Forward: AATGGTGAAGGCTGGTTTTG \\
(AtActin7) Reverse: TGCCTCTGTGAGTAGAACTG \\
At4g14560 Forward: TGGTCGAGGCAAAAACAAAT \\
(AtIAA1) Reverse : AAACTTCGTATAATCAAAACTCATCTT \\
At5g44420 Forward: TCTTTGGTGCTAAATCGTGTG \\
(AtPDF1.2) Reverse : AACAACAACGGGAAAATAAACA \\
\hline
\end{tabular}

leaves. The cDNA of UGT74E2 was synthesized by using $3 \mu \mathrm{g}$ of total RNA, oligo (dT) primer and superscript reverse transcriptase (Promega, USA) according to the manufacturer's instruction. The UGT74E2 gene-specific primer pairs were used for PCR (Supplemental Table 2). The PCR amplification was performed at $95^{\circ} \mathrm{C}$ for $30 \mathrm{~S}$, $56^{\circ} \mathrm{C}$ for $30 \mathrm{~S}$, and $72^{\circ} \mathrm{C}$ for $30 \mathrm{~S}$ for 33 cycles. After $\mathrm{PCR}$, the amplified samples were size-fractionated on $1 \%$ agarose gel, and the resolved fragments were eluted, cloned into pGEM-T Easy vector (Promega, USA), and sequenced. DNA sequence data were assembled and analyzed with DNASTAR package (DNAstar, USA). Database searches were performed with the NCBI BLAST program (www. ncbi.nlm.nih.gov/BLAST/).

\section{Results}

Selection of SA-inducible genes and genetic screening of T-DNA insertion lines which show impaired response to salicylic acid treatment. To identify further components of the defense mechanism in Arabidopsis thaliana, we investigated expression changes in A. thaliana under 18 different biotic or abiotic conditions using a DNA microarray representing approximately $25 \%$ of all $A$. thaliana genes on the web site (www.genevestigator.com). Analysis using GENEVESTIGATOR software showed that expression of over 42 genes in Arabidopsis is affected by SA application (data not shown). Among the 42 genes, we chose genes which were early responsive to SA treatment and whose biological functions have not been characterized so far (Table 3). To investigate biological meaning, we obtained available T-DNA insertion mutants of the above 17 genes from SALK institiute (http://signal.salk.edu). We finally obtained genuine homozygotes through the mutant geno-

Table 3. Summary of Arabidopsis SA-inducible gene mutants used in this study and their local resistance to Pst DC3000

\begin{tabular}{|c|c|c|c|c|}
\hline AGI & Polymorphism $^{\mathrm{a}}$ & Gene description & $\log _{2} \mathrm{SA}^{\mathrm{b}}$ & $\begin{array}{l}\text { Level of symp- } \\
\text { tom change }(\%)^{c}\end{array}$ \\
\hline At4g35180 & SALK_027033 & Lys/His transporter 7 (HLT7) & 4.51 & 35.0 \\
\hline At $\lg 15640$ & SALK_001121 & Unknown protein & 2.88 & 30.0 \\
\hline At $\lg 44050$ & SALK_011264 & DC1 domain-containing protein & 2.68 & 23.1 \\
\hline At5g59490 & SALK_080547 & Haloacid dehalogenase-like hydrolase family protein & 3.18 & 22.6 \\
\hline Atlg17170 & SALK_034472 & Glutathione S-transferase TAU 24 (ATGSTU24) & 3.68 & 11.8 \\
\hline At3g23190 & SALK_123883 & Lesion inducing protein-related & 2.41 & 0.8 \\
\hline At $2 g 14560$ & SALK_039201 & Late upregulated in response to Hyaloperonospora parasitica (LURP1) & 5.35 & -1.3 \\
\hline At5g11920 & SALK_152299 & 6- \& 1-fructan exohydrolase (AtCWINV6) & 3.89 & -1.7 \\
\hline At3g56400 & SALK_025198 & WRKY DNA-binding protein 70 (ATWRKY70) & 4.88 & -3.8 \\
\hline At $\lg 29020$ & SALK_062045 & Calcium-binding EF hand protein & 3.67 & -4.4 \\
\hline At4g10500 & SALK_059907 & Subtilase family protein & 4.94 & -6.6 \\
\hline Atlg50090 & SALK_070362 & Aminotransferase class IV protein & 2.78 & -11.8 \\
\hline At $2 g 40750$ & SALK_095417 & WRKY DNA-binding protein 54 (ATWRKY54) & 8.54 & -16.3 \\
\hline At3g53480 & SALK_035704 & Pleiotropic drug resistance 9 (PDR9) & 2.41 & -17.5 \\
\hline At $2 g 04050$ & SALK_142350 & MATE efflux family protein & 1.93 & -19.0 \\
\hline At $\lg 05680$ & SALK_016116 & UDP-glucoronosyl/UDP-glucosyl transferase family protein & 5.1 & -22.5 \\
\hline At5g45070 & SALK_143717 & Phloem protein 2-A8 (AtPP2-A8) & 3.82 & -47.2 \\
\hline
\end{tabular}

${ }^{a}$ All T-DNA insertion mutants are in Columbia-0 background.

${ }^{b}$ This expression data reference is from GENEVESTIGATOR and designates changed expression levels of the genes treated by salicylic acid. ${ }^{\mathrm{c}}$ Relative disease severity on 17 T-DNA insertion mutants (SALK) at $5 \mathrm{dpi}$ upon Pst DC3000 infection $\left(1 \times 10^{7} \mathrm{cfu} / \mathrm{ml}\right) \mathrm{by} \mathrm{dipping}$. 


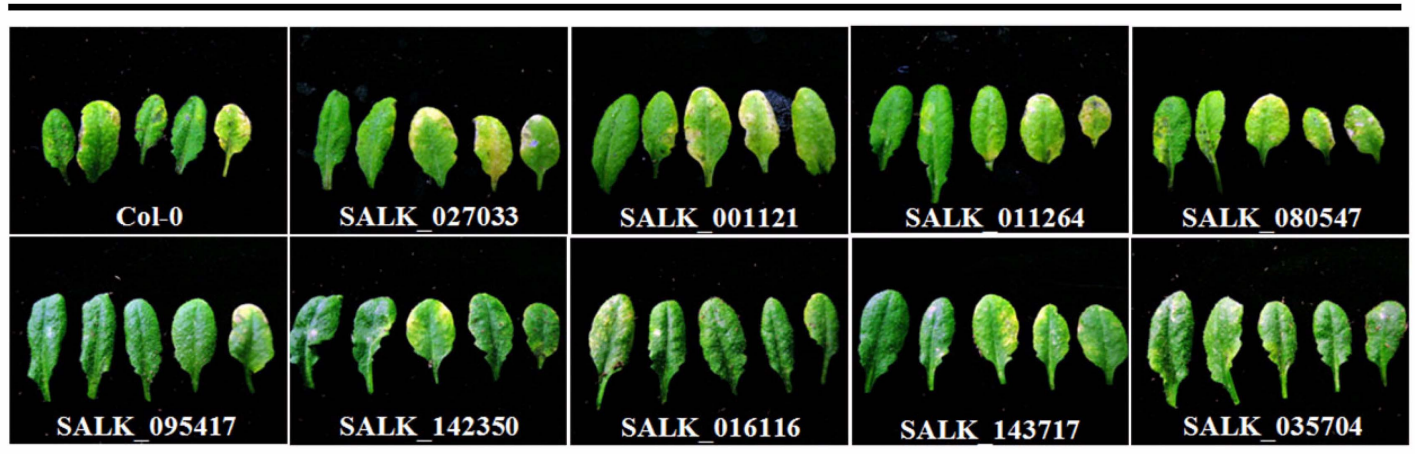

B

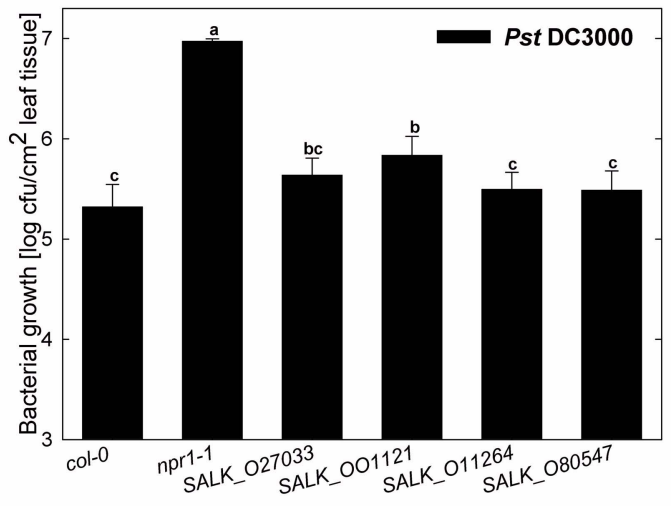

C

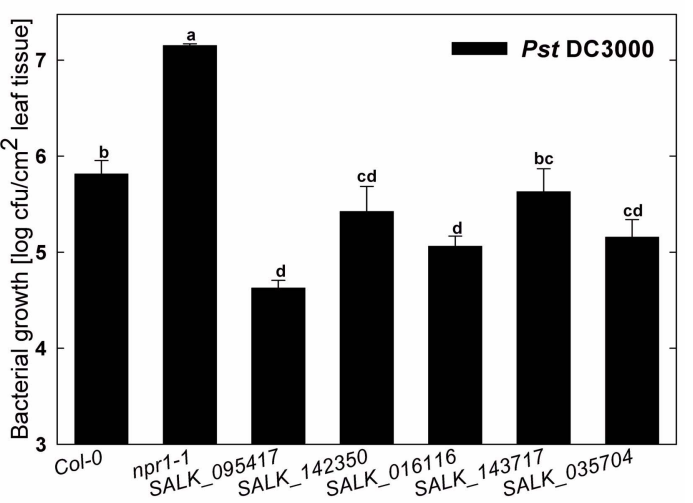

Fig. 1. Growth comparison of $P$. syringae pv. tomato DC3000 in Arabidopsis Col-0, npr1-1, and T-DNA insertion mutants. Leaves were vacuum infiltrated with $5 \times 10^{4} \mathrm{cfu} / \mathrm{ml}$ of bacteria and in planta bacterial populations were determined at 3 day post infiltration. Bacterial growth represents the bacterial titers of three pooled discs in three replicates. The experiment was repeated three times with similar results. (A) Symptoms development by Pst DC3000 on Col-0 and 9 homozygous T-DNA insertion lines. (B) and (C) Bacterial recovery of Pst DC3000 on Col-0, npr 1-1, and mutants. According to the Duncan's multiple range test $(P=0.05)$, means with the same letter are not significantly different. Error bar indicates SD $(n=3)$.

typing.

Monitoring of disease resistance in SA-inducible gene knock-out mutants. To elucidate the biological function of each gene in defense response, virulent bacterial pathogen Pst DC3000 that is known to be associated in SA-dependent defense signaling pathway in Arabidopsis was inoculated on the leaves of knock-out plants using dipping method as described by Katagiri et al. (2002). High concentration of inoculum $\left(1 \times 10^{7} \mathrm{cfu} / \mathrm{ml}\right)$ was used for observation of bacterial speck development. Then we assessed bacterial symptoms including chlorotic and necrotic lesions in rosette leaves. As shown in the Table 3, several mutants exhibited increased bacterial speck symptoms on the leaves and other mutant lines showed decreased symptoms against $P s t$-infection compared to wild type Col- 0 . Among these mutants, four T-DNA insertion mutants that showed more than $20 \%$ of increased-symptom and five T-DNA insertion mutants that exhibited more than $15 \%$ of decreased-symptom than those in wild type were collected for further work. To investigate more detailed disease response change against Pst-infection, above nine T-DNA insertion mutants were inoculated with virulent Pst DC3000 using vacuum infiltration method. To recover the bacterial pathogen, a concentration of bacterial inoculum was moderate $\left(5 \times 10^{4}\right.$ $\mathrm{cfu} / \mathrm{ml}$ ) at this time for confirmation of the disease response change in mutant plants. When bacterial populations were recovered at 3 days post inoculation (dpi), there were actual differences between wild type and mutants. In terms of bacterial growth, there were not so much differences in symptom-increased group compared to wild-type. But the bacterial growth was lower than that of wild-type ( $>$ threefold) in some cases of symptom-decreased group (Fig. 1). Next to check whether these genes are also associated with defense response against fungal invasion, fungal growth assay was performed in planta. Alternaria brassicicola involved in ethylene/jasmonate signaling was used in the experiments. Overall there were not so significant differences in fungal infection (Fig. 2). Similar results were obtained in the case of Botrytis cineria infection (data not 
A Alternaria brassicicola ( $5 \times 10^{4}$ spores $\left./ \mathrm{ml}, 5 \mathrm{dpi}\right)$

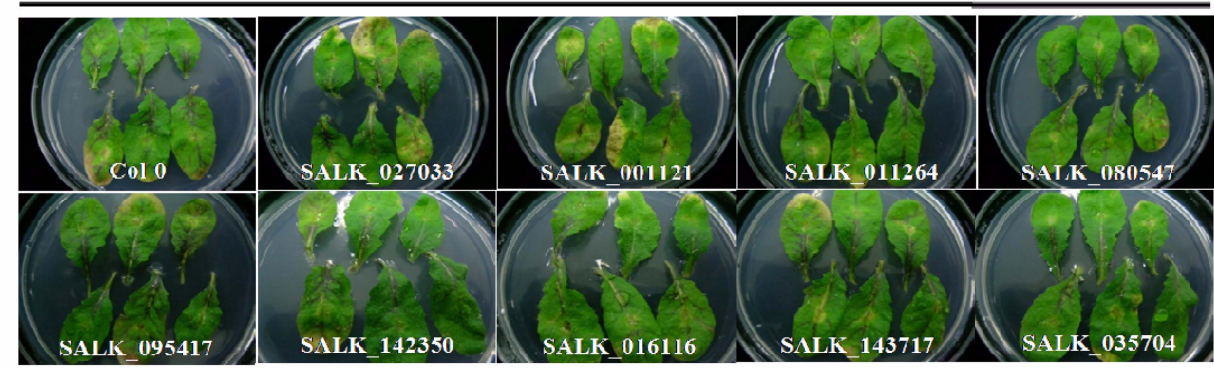

$\mathrm{B}$



Fig. 2. Growth of fungal pathogens in Arabidopsis T-DNA insertion mutants. (A) Pathogenesis of Alternaria brassicicola on Col-0 and mutant plants. Picture was taken 5 days after infection. (B) Relative lesion size of Alternaria brassicicola growth on Col-0 and mutant plants. Leaves were inoculated with $5 \times 10^{4}$ spores $/ \mathrm{ml}$ and in planta fungal growth was measured as a lesion diameter at 5 days post inoculation. According to the Duncan's multiple range test $(P=0.05)$, means with the same letters are not significantly different. Error bar indicates $\mathrm{SD}(\mathrm{n}=3)$.

shown). These results indicate that these genes may besalicylic acid dependent but jasmonate/ethylene independent, and these genes may be associated with bacterial disease resistance in Arabisopsis.

At1g05680 encodes UGT74E2 that belongs to Arabidopsis UGT group L member. Among nine mutants, one member of AtUGT mutant (SALK_016116; At Ig05680) that showed relatively strong enhanced resistance was of our particular interest (Fig. 1C). Since glycosylation is an integral step in modification of numerous secondary metabolites to stable and soluble forms by transferring sugars (Lim and Bowles, 2004) and the actual functions of AtUGTs in plantpathogen interaction are still unknown, we performed further studies with this AtUGT. The insertion site of T-DNA in this UGT mutant was second exon (Fig. 3A) and the mutant used at this study was genuine homozygous mutant, as confirmed by genotyping (Fig. 3B). In the previous reports, group D members of UGT gene family were known to be associated with defense response against pathogen in planta (Chong et al., 2002; Gachon et al., 2004; LangloisMeurinne et al., 2005). Also a previous report showed the partial biological functions of $U G T 73 D 1$ that are induced by SA treatment and Pst DC3000-infection (LangloisMeurinne et al., 2005). However, there was no information about exact biological functions that are involved in plant defense of other groups of UGT family. The At $1 g 05680$ encodes a protein of 413 amino acids. To analyze sequence homology between this $A t U G T$ and other members of Arabidopsis UGT gene superfamily, amino acid sequence analysis was performed. In the case of At 1 g05680, putative coding protein was completely identical with UGT74E2 
that belongs to an Arabidopsis UGT group L member (Fig. 3D). When compared with several other Arabidopsis UGT group L members, this UGT74E2 protein showed strong homology with UGT74E1 throughout the entire coding


Fig. 3. Analysis of genomic organization, T-DNA insertion mutant, and phylogenetic tree of Arabidopsis UGT74E2. (A) Genomic structure of $U G T 74 E 2$ and location of T-DNA insertion in UGT74E2 mutant. (B) Genotyping of UGT74E2 mutant by using $U G T 74 E 2$ gene-specific primer pair and T-DNA border primer (LBa1). (C) Alignment analysis of UGT74E2 (At1g05680) and other AtUGTs belonging to the L group. Amino acid sequences comparison was done with the $\mathrm{C}$ termini of the AtUGT group $\mathrm{L}$ member proteins. Multiple sequence alignment was performed with the DNAstar package. Black shading shows amino acid identities. Underlining indicates the signature sequence (PSPG box, plant secondary product glycosyltransferase) of glycosyltransferases. The conserved domain of UGT is boxed. (D) Phylogenetic tree analysis of At1g05680 and other AtUGTs belonging to the group L. DNA sequence data were assembled and analyzed with DNASTAR package (DNAstar, USA). Database searches were performed with the NCBI BLAST program (www.ncbi.nlm.nih.gov/BLAST/). region (about 82\%), including the PSPG-box (Fig. 3C). In general, this AtUGT family member using alignment analysis showed considerable homology (about 30 to $80 \%$ ) in the C-terminal region including the PSPG-box but they exhibited rather weak homology in other regions. This amino acid sequence alignment analysis indicates that UGT74E2 retained the features of the Arabidopsis UGT superfamily.

$U G T 74 E 2$ expression is organ-specific and is induced by biotic and abiotic stress treatments. To verify whether the expression of UGT74E2 is induced in organ-specific manner, RT-PCR analysis was performed by using UGT74E2 genespecific primer pair. RNA was extracted from typical organs of Arabidopsis such as root, stem, flower, and rosette leaf. In the case of $U G T 74 E 2$, the gene was strongly expressed in flower compared to the other organs such as root and

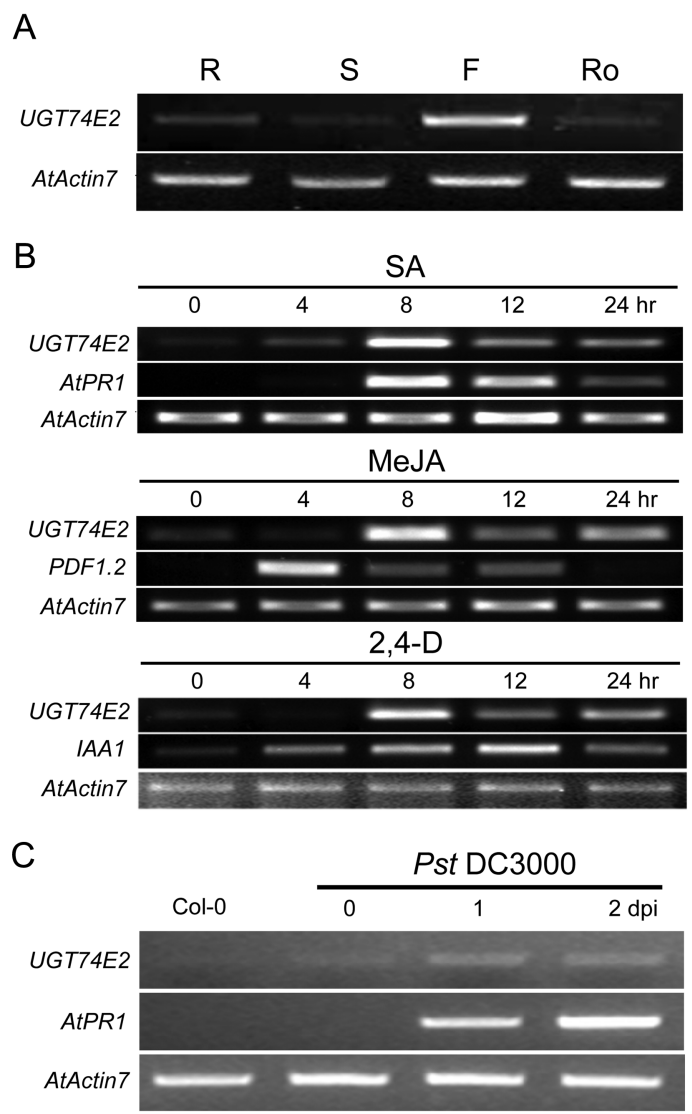

Fig. 4. Analysis of UGT74E2 gene expression in Col-0. (A) Organ specific expression patterns of $U G T 74 E 2$ gene in each organ of Col-0 plant. The abbreviation for Arabidopsis organs is following: R, Root; S, Stem; F, Flower; Ro, Rosette leaves. (B) Gene expression pattern of $U G T 74 E 2$ in response to hormone treatments. Three-week-old Col-0 seedlings grown in MS media were treated with SA $(1 \mathrm{mM})$, MeJA $(50 \mu \mathrm{M})$, and 2,4-D $(20 \mu \mathrm{M})$ and rosette leaves were harvested at the time points indicated. (C) Expression pattern of UGT74E2 gene upon inoculation with Pst DC3000. 


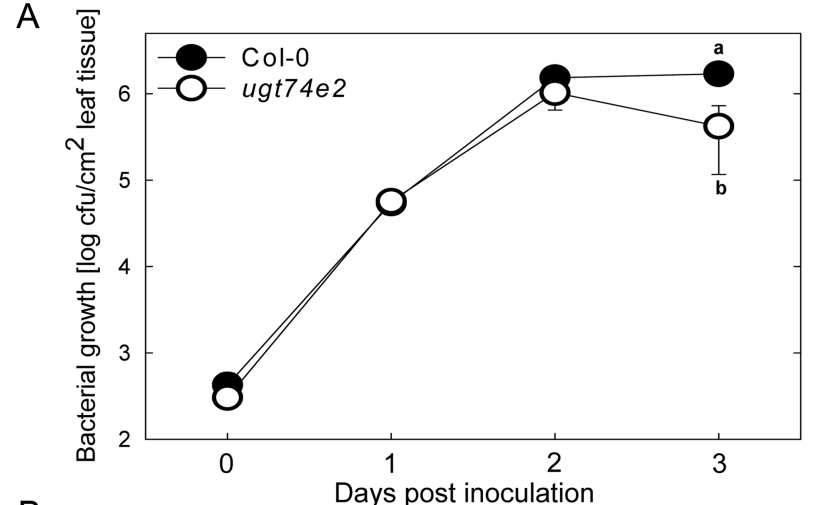

B

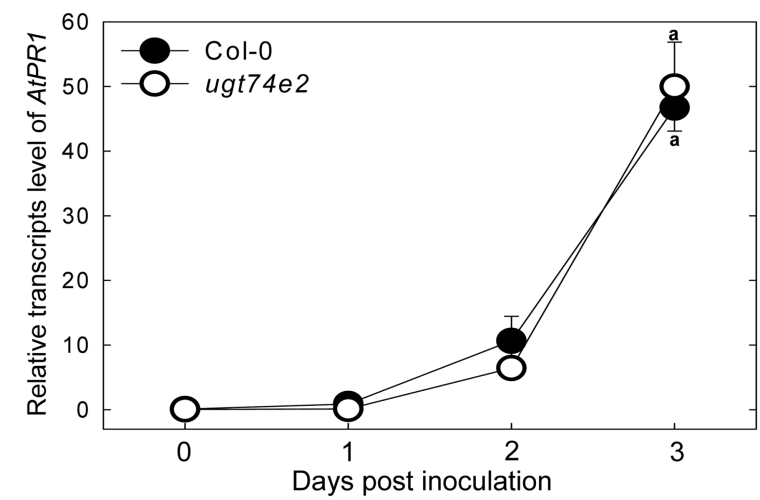

C

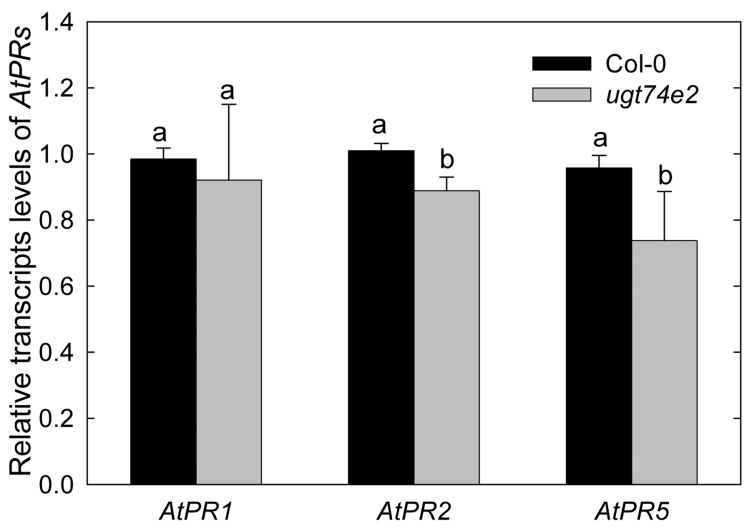

Fig. 5. Changed disease resistance in UGT74E2 mutant against Pst DC3000 infection. Multiplication of Pst DC3000 in Col-0 and UGT74E2 mutant leaves. Leaves were inoculated with $5 \times 10^{4}$ $\mathrm{cfu} / \mathrm{mL}$ of bacteria and in planta bacterial populations were determined at $0,1,2$ and 3 days post infiltration. For each time frame, six leaf discs were taken from Pst DC3000-inoculated Arabidopsis leaves, ground in $10 \mathrm{mM} \mathrm{MgCl}$, and plated in five 10 -fold dilutions. The dilution factor of each sample is from $10^{\circ}$ to $10^{-5}$. The plate was incubated at $28^{\circ} \mathrm{C}$ for 2 days. Multiplication of Pst DC3000 in each plant was plotted on a log scale (A) Determination of the bacterial population in inoculated leaf tissue at 3 dpi. (B) and (C) Quantitative real-time PCR expression profiles of AtPRs after Pst DC3000 infiltration in Col-0 and $U G T 74 E 2$ mutant. Relative transcripts level of AtPR1 gene was determined at 0, 1, 2, and $3 \mathrm{dpi}(\mathrm{B})$ and those of AtPR2 and AtPR5 genes were determined at $3 \mathrm{dpi}(\mathrm{C})$. According to the Duncan's multiple range test $(P=0.05)$, means with the same letter are not significantly different. Error bar indicates $\operatorname{SD}(n=3)$. stem (Fig. 4A). This expression pattern is identical with a dataset shown on GENEVESTIGATOR. This result indicates that UGT74E2 gene expresses with organ-specific manner. In silico data suggested that UGT74E2 is strongly expressed upon typical phytohormones (salicylic acid, methyl jasmonic acid, and ABA) and chemicals (2,4-dichlorophenoxyacetic acid, $\mathrm{AgNO}_{3}$ and so forth) treatments. To assess whether UGT74E2 is actually expressed upon hormone and chemical treatments, RT-PCR analysis was performed by using $U G T 74 E 2$-specific primer after SA, MeJA, and 2,4-D treatments on early seedlings. As shown in Fig. 4b, UGT74E2 was expressed at relatively early time points $(8 \mathrm{~h})$ upon hormone and chemical treatments. These results indicate that this gene is induced by wide range of stress conditions. To identify whether UGT74E2 gene is actually induced upon Pst-infection, RT-PCR analysis was performed by using gene-specific primers of UGT74E2. For this analysis, Pst DC3000 inoculum $\left(5 \times 10^{4} \mathrm{cfu} / \mathrm{ml}\right)$ was infiltrated into plants by using vacuum infiltration method. Arabidopsis leaves were collected at 0, 1, and 2 days post inoculation (dpi) and also non-treated leaves of same time points were collected as control. The UGT74E2 expression level was increased gradually from 1 to $2 \mathrm{dpi}$. AtPR1 as a marker gene of SA-mediated defense against biotrophs or hemibiotrophs was significantly induced by Pst-infection (Fig. 4C). This result suggests that UGT74E2 is induced by Pst DC3000-infection and the expression patterns of this gene coincide with those of in silico data.

UGT74E2 mutant shows moderately increased resistance to Pst DC3000-infection in local infected leaves. To examine the function of UGT74E2 on defense response against $P s t$-infection, defense activation was directly compared from Col-0 and UGT74E2-deficient mutant through the inoculation with virulent Pst DC3000 strain and by determination of bacterial recovery at $0,1,2$, and $3 \mathrm{dpi}$. There was no difference in bacterial growth between Col-0 and UGT74E2 mutant until 2 dpi. But, bacterial growth was significantly inhibited (about 7 fold) in UGT74E2 mutant compared to those of Col-0 at 3 dpi (Fig. 5A). To explain the reason for enhanced resistance against Pst DC3000 in UGT74E2 mutant, we assessed a change of typical marker gene, AtPRl, which is well known to be involved in SA-mediated defense signaling pathway. When the virulent strain Pst DC3000 was infiltrated in UGT74E2-deficient mutant, There was no difference in expression of AtPR1 in mutant plants compared to those of Col-0 (Fig. 5B and 5C). Because of no difference on AtPRl-induction, we investigated the changes of other pathogenesis-related genes, AtPR2 and AtPR5 in Col-0 and UGT74E2 mutant at 3 dpi. In the case of AtPR2 and $A t P R 5$, those transcripts accumulation were slightly less induced by Pst DC3000 in UGT74E2 mutant plants 


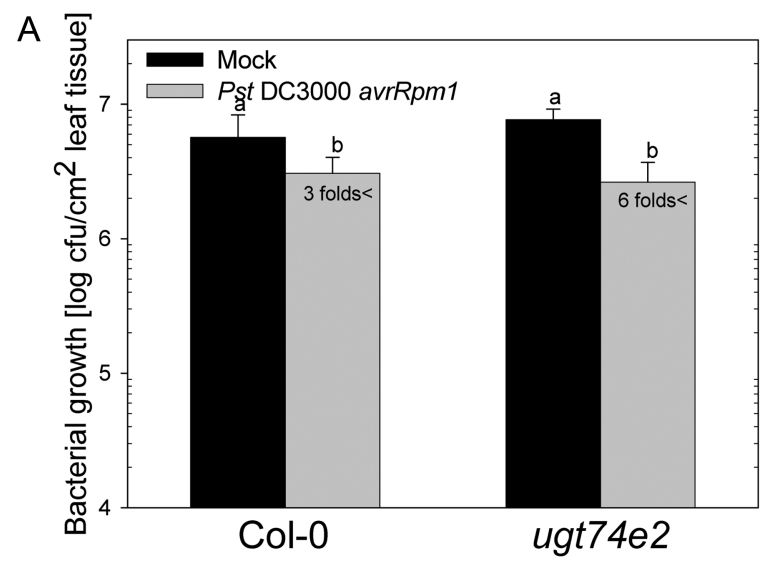

$\mathrm{B}$

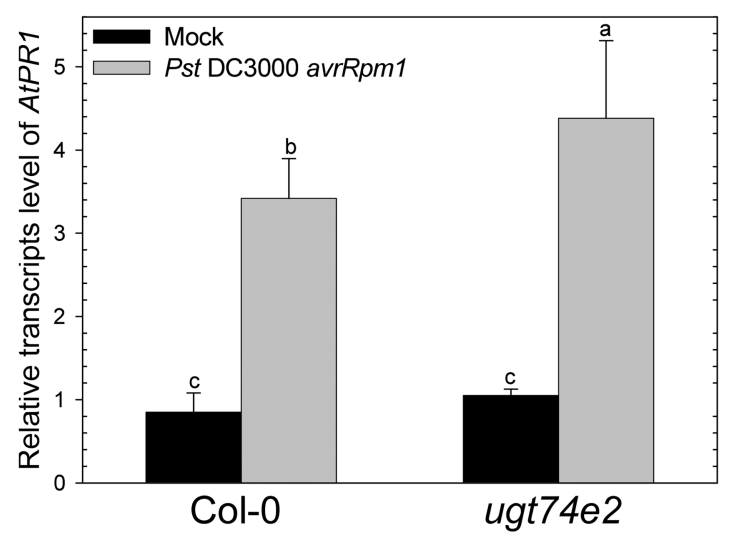

C

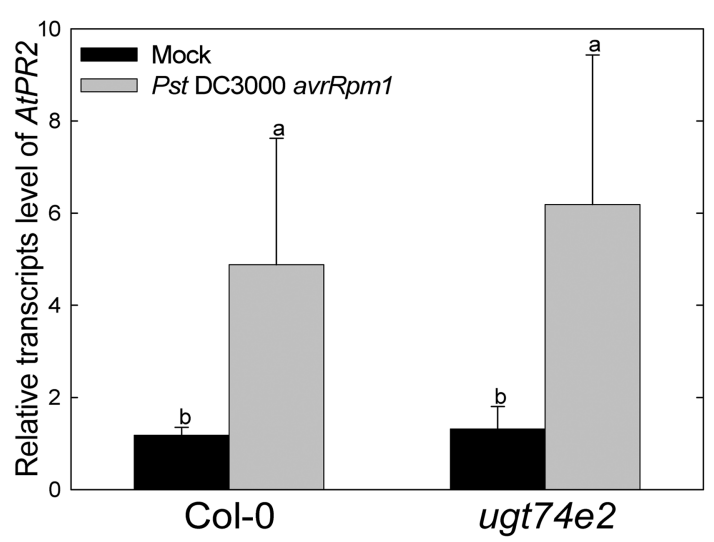

D

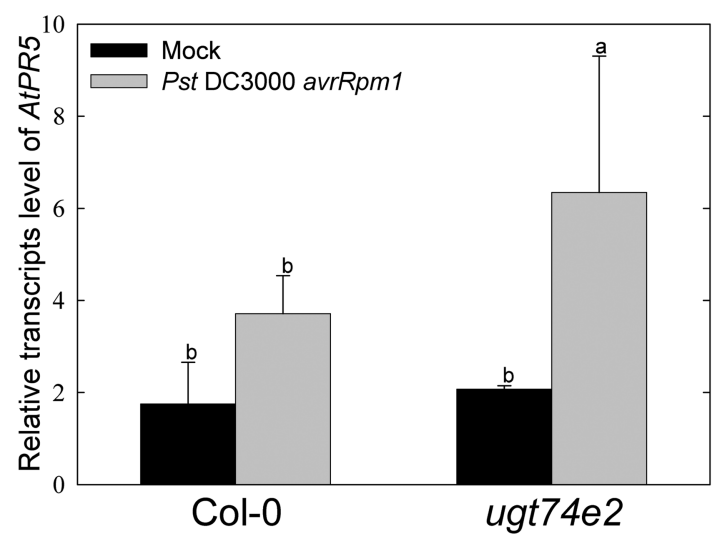

Fig. 6. Systemic acquired resistance assay in $U G T 74 E 2$ mutant. (A) Bacterial growth in uninduced (Mock, $10 \mathrm{mM} \mathrm{MgCl}_{2}$ ) and induced (Pst DC3000 avrRpm1 inoculation) Col-0 and UGT74E2 mutant. SAR was monitored by comparing growth of virulent Pst DC3000 in Col-0 and UGT74E2 mutant at 3 days post secondary inoculation. Quantitative real-time PCR expression profiles of AtPRs, (B) AtPR2, (C) and AtPR5, (D) in systemic leaves of uninduced (Mock, $10 \mathrm{mM} \mathrm{MgCl}$ ) and induced (Pst DC3000 avrRpml) Col-0 and UGT74E2 mutant. SAR was monitored by comparing expression of defense-related genes at 3 days post inoculation. And at least three independent experiments were carried out. According to the Duncan's multiple range test $(P=0.05)$, means with the same letter are not significantly different. Error bar indicates SD $(n=3)$.

compared to those of Col-0 at 3 dpi (Fig. 5B and 5C). These results indicate that $U G T 74 E 2$ mutant exhibited slightly enhanced local resistance to Pst DC3000-infection, not through some $P R$-mediated system.

Functions of $U G T 74 E 2$ in systemic immunity. In the bacterial growth assay, UGT74E2 mutant showed an enhanced-resistance against Pst DC3000 infection (Fig. 5A). Moreover, this gene was isolated from genetic screening of SA-inducible genes. So, we at first postulated that transcripts accumulation of AtPRI gene would be elevated in UGT74E2 mutant compared to those of Col-0. However, the AtPR1 expression was not changed and the expression level of AtPR2 and AtPR5 was even rather slightly decreased in UGT74E2 mutant (Fig. 5B and 5C). As shown in previous report, a glycosylated form of SA plays an important role during biological processes in planta (Dean et al., 2005). Thus, as a next step, to see whether UGT74E2 is involved in SAR in Arabidopsis, SAR assay was performed. SAR was induced by inoculating two or three leaves with avirulent $P s t$ DC3000 strain carrying avrRpm 1 $\left(1 \times 10^{6} \mathrm{cfu} / \mathrm{ml}\right)$ or $10 \mathrm{mM} \mathrm{MgCl} 2$ as mock control. And then, upper leaves were challenged with virulent $P s t$ DC3000 strain $\left(5 \times 10^{4} \mathrm{cfu} / \mathrm{ml}\right)$ after 3 days post primary inoculation. As shown in the Fig. 6a, bacterial growth of Pst DC3000 was decreased in UGT74E2 mutant compared to Col-0 plant ( $>$ ten-fold). SAR was also monitored by comparing expression levels of $P R \mathrm{~s}$ in Col-0 and UGT74E2 mutant using RT-qPCR analysis. As shown in the Fig. 6b, the $A t P R 1$ as well as $A t P R 2$ and $A t P R 5$ expression levels of $U G T 74 E 2$-deficient mutant were increased compared to Col-0 ( $>$ three-fold). (Fig. 6C and 6D).

To confirm the role of UGT74E2 in the SA-mediated defense signaling pathway, we investigated the expression patterns of UGT74E2 in SA-deficient npr 1-1 mutant and $N a h G$ transgenic plant after Pst DC3000-inoculation by 


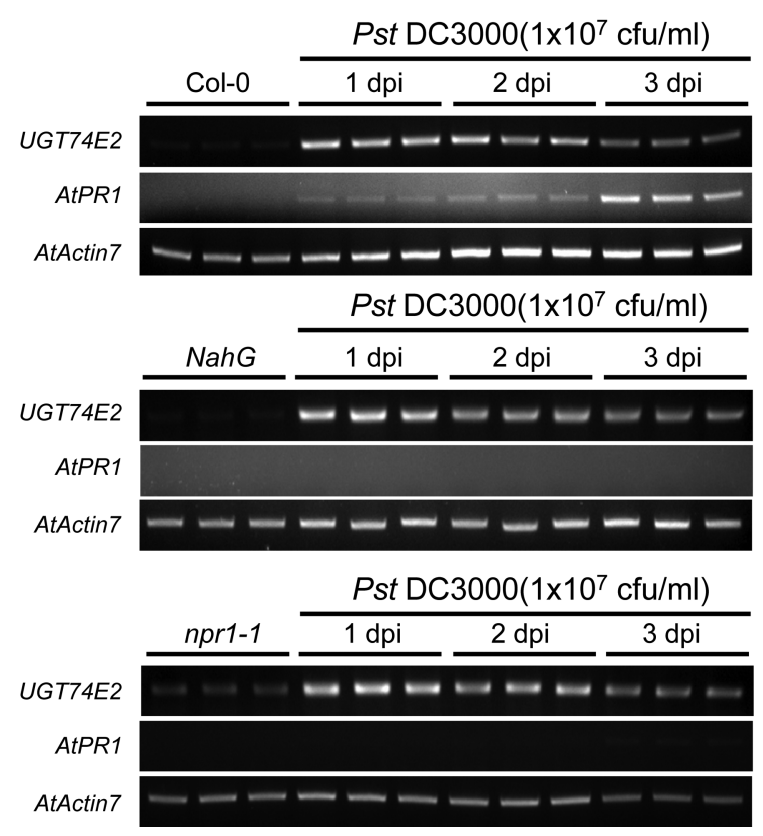

Fig. 7. Expression patterns of UGT74E2 in SA-deficient mutants, NahG and $n p r 1-1$, after Pst-infection. Leaves were inoculated with $1 \times 10^{7} \mathrm{cfu} / \mathrm{mL}$ of Pst DC3000 by spray method and transcripts level of $U G T 74 E 2$ was determined at 1,2 and 3 days post inoculation in Col-0 and UGT74E2 mutant. AtPRI was used as a positive control.

using RT-PCR analysis. We found that transcripts level of UGT74E2 was not much different in SA-deficient mutants compared to those of Col-0 (Fig. 7). We also investigated the endogenous SA level in Col-0 and UGT74E2 mutant during the process of SAR. However, there was no difference between them (data not shown). These results suggest that UGT74E2 may not be directly involved in SA-dependent defense signaling pathway.

\section{Discussion}

The large-scale genomic sequencing that has been undertaken in some plants provides sequence of each gene. However, understanding of gene function remains behind the pace of genome sequencing. In Arabidopsis, the putative functions of more than half of its whole genes are unknown (The Arabidopsis Genome Initiative, 2000). For a better utilization of sequencing information, high-throughput methods for assessment of functions are required. The application of microarray technology to plant gene expression analysis has been continuously accumulated (Seki et al., 2001; Wang et al., 2000), and initial microarray experiments on plant responses to certain stimuli have already shown promise for functional characterization of important processes such as plant defense. The use of the Affymetrix ATH1 array (Redman et al., 2004) resulted in over 20,000 genes expression data. The GENEVESTIGATOR software, with the ability to query a database of 1,561 publically available Arabidopsis microarray datasets, has recently been available online (Zimmermann et al., 2004). Analysis using GENEVESTIGATOR software shows expression of over 42 genes in Arabidopsis that are specifically induced by SA application and also by Pst-infection (data not shown).

Salicylic acid is a crucial component in plant defense signaling network during pathogen invasion. Through the bacterial symptom counting assay and bacterial growth assay at this time with the bacterial pathogen, Pst DC3000, we confirmed that there was significant change in typical defense responses such as chlorosis and necrosis in some TDNA insertional mutants of the above candidate genes compared to wild-type (Col-0) (Table 1 and Fig. 1). Through this reverse-genetic approach by using gene expression data in silico and T-DNA mutagenized-polymorphism, it could be identified that these SA-inducible genes are actually associated with plant defense mechanism.

As shown in Fig. 4, it is likely that UGT74E2 is induced by many stress treatments. From these results, it is speculated that UGT74E2, as a member of UGT group L, is involved in stress response in Arabidopsis.

Even though the UGT74E2-deficinet mutant showed enhanced resistance against $P$ st DC3000-infecton (Fig. 1c; Fig. 5a), the expression patterns $P R 1$ genes (AtPR1, AtPR2, and AtPR5) in Col-0 and the mutant were not much different at the site of infection (Fig. 5B, C). Since Pst DC3000 is a virulent strain in this case, the expression of $P R$ s would not have contributed much. We thus performed the SAR assay to determine the functional roles of UGT74E2 gene in systemic immunity. We could confirm the increasedchanges of systemic resistance of UGT74E2 mutant during the process of SAR (Fig. 6A). Also, transcripts accumulation of AtPR1, AtPR2, and AtPR5 was increased in UGT74E2 mutant ( $>3$-fold) compared to those of mock control (Fig. $6 \mathrm{~B}, 6 \mathrm{C}$, and $6 \mathrm{D})$. The roles of UGT in disease resistance have been reported in the past. In tobacco plants carrying the $N$ gene, SA GTase (SA UDP-glycosyltransferase) mRNA was induced by bacterial or viral pathogen (Lee and Raskin, 1999). Recent report showed that CaUGT1 is associated with disease resistance against Tobacco mosaic virus (TMV) in Capsicum annum L. Bugang (Lee et al., 2009). Among the UGT super family in Arabidopsis, only group D members were known to be involved in disease resistance (Langlois-Meurinne et al., 2005). Moreover, it was not clearly defined what is the crucial component for SAR induction is in Arabidopsis to date.

UGT74E2 is a member of the group L subclass of UGTs (Ross et al., 2001), which includes Arabidopsis UGT84B1, described as auxin glycosyltransferase, and UGT74F2, which has been recognized previously as SA and anthranilate (a 
Trp precursor) glycosyltransferase (Jackson et al., 2001; Quiel and Bender, 2003; Song, 2006).

From the results of SAR assay, it could be speculated that SAR was enhanced in UGT74E2 mutant. These results emphasize that plant acceptor for glycosylation including hormones (ABA, auxin, cytokinin, SA, and brassinosteroids), secondary metabolites (anthranilate, caffeic acid, and flavonoids), and xenobiotics (Ross et al., 2001) plays an important role in the plant-pathogen interaction, especially in SAR system. Recently, UGT74E2 has been reported to glycosylate auxin indole-3-butyric acid (IBA) preferentially. Also ectopic overexpression of UGT74E2 in Arabidopsis altered plant architecture and improved stress tolerance (Tognetti et al., 2010).

Through the result of local and SAR assay, it could be postulated that glycosylation of auxin by UGT74E2 contributes to disease susceptibility in local and systemic tissues. Previous studies have shown that the levels of indole-3acetic acid (IAA), the primary plant auxin, increased in plant tissues infected by Pst DC3000 (O'Donnell et al., 2003). Microarray analysis has shown that infection with Pst DC3000 activates genes related to IAA biosynthesis and represses Aux/IAA family and auxin transporter genes (Thilmony et al., 2006). Microarray analysis in response to SA analog, benzothiadiazole S-methylester (BTH), also has shown repression of 21 genes related with auxin signal transduction, implying that BTH might affect auxin homeostasis (Wang et al., 2007). Conversely, the Arabidopsis miR393a is induced by the flagellin-derived peptide flg22 and represses auxin signaling through down-regulating the auxin receptor, resulting in increased resistance to $P$. syringae (Navarro et al., 2006). Together, these results suggest that auxin plays an important role in disease resistance and susceptibility.

\section{Acknowledgments}

This work was supported by Grants from the National Research Foundation of Korea to the Plant Signaling Network Research Center (R11-2003-008-02001-0) and Midcareer Researcher Program (2009-0085565), and the Wujangchoon Project from Rural Development Administration of Korea (PJ00785020).

\section{References}

Beckers, G. J. M. and Spoel, S. H. 2006. Fine-tuning plant defence signalling: salicylate versus jasmonate. Plant Biol. 8:1-10.

Chong, J., Baltz, R., Schmitt, C., Beffa, R., Fritig, B. and Saindrenan, P. 2002. Downregulation of a pathogen-responsive tobacco UDP-glc: phenylpropanoid glucosyltransferase reduces scopoletin glucoside accumulation, enhances oxidative stress, and weakens virus resistance. Plant Cell 14:1093-1107.

Dangl, J. L. and Jones, J. D. 2001. Plant pathogens and integrated defence responses to infection. Nature 411:826-833.

Dean, J. V., Mohammed, L. A. and Fitzpatrick, T. 2005. The formation, vacuolar localization, and tonoplast transport of salicylic acid glucose conjugates in tobacco cell suspension cultures. Planta 221:287-296.

Delaney, T. P., Uknes, S., Vernooij, B., Friedrich, L., Weymann, K., Negrotto, D., Gaffney, T., Gut-Rella, M., Kessmann, H., Ward, E. and Ryals, J. 1994. A central role of salicylic acid in plant disease resistance. Science 266:1247-1250.

Dempsey, D., Shah, J.and Klessig, D. 1999. Salicylic acid and disease resistance in plants. Crit. Rev. Plant Sci. 18:547-575.

Durrant, W. E. and Dong, X. 2004. Systemic acquired resistance. Annu. Rev. Phytopathol. 42:185-209.

Falk, A., Feys, B. J., Frost, L. N., Jones, J., Daniels, M. J. and Parker, J. E. 1999. EDS1, an essential component of $R$ genemediated disease resistance in Arabidopsis has homology to eukaryotic lipases. Proc. Natl. Acad. Sci. USA 96:3292-3297.

Ferrari, S., Plotnikova, J. M., De Lorenzo, G. and Ausubel, F. M. 2003. Arabidopsis local resistance to Botrytis cinerea involves salicylic acid and camalexin and requires EDS4 and PAD2, but not SID2, EDS5 or PAD4. Plant J. 35:193-205.

Gaffney, T., Friedrich, L., Vernooij, B., Negrotto, D., Nye, G., Uknes, S., Ward, E., Kessmann, H. and Ryals, J. 1993. Requirement of salicylic acid for the induction of systemic acquired resistance. Science 261:754-756.

Gachon, C., Baltz, R. and Saindrenan, P. 2004. Over-expression of a scopoletin glucosyltransferase in Nicotiana tabacum leads to precocious lesion formation during the hypersensitive response to tobacco mosaic virus but does not affect virus resistance. Plant. Mol. Biol. 54:137-146.

Gachon, C., Langlois-Meurinne, M. and Saindrenan, P. 2005. Plant secondary metabolism glycosyltransferases: the emerging functional analysis. Trends Plant Sci. 10:542-549.

Glazebrook, J. G. 2005. Contrasting mechanisms of defense against biotrophic and necrotrophic pathogens. Annu. Rev. Phytopathol. 19:309-331.

Hancock, J. G. and Huisman, O. C. 1981. Nutrient movement in host-pathogen systems. Annu. Rev. Phytopathol. 19:309-331.

Jackson, R. G., Lim, E.-K., Li, Y., Kowalczyk, M., Sandberg, G., Hoggett, J., Ashford, D. A. and Bowles, D. J. 2001. Identification and biochemical characterization of an Arabidopsis indole3-acetic acid glycosyltransferase. J. Biol. Chem. 276:43504356

Jones, J. D. and Dangl, J. L. 2006. The plant immune system. Nature 444:323-329.

Katagiri, F., Thilmony, R. and He, S. Y. 2002. The Arabidopsis thaliana-Pseudomonassyringae Interaction. In The Arabidopsis Book, Somervill C.R., Meyerowitz E.M., eds. (Rockville, American Society of Plant Biologists), pp. 1-35.

Kunkel, B. N. and Brooks, D. M. 2002. Cross talk between signaling pathways in pathogen defense. Curr. Opin. Plant Biol. 5:325-331.

Langlois-Meurinne, M., Gachon, C. and Saindrenan, P. 2005. Pathogen-responsive expression of glycosyltransferase genes 
$U G T 73 B 3$ and $U G T 73 B 5$ is necessary for resistance to Pseudomonas syringae pv tomato in Arabidopsis. Plant Physiol. 139:1890-1901.

Lee, B. J., Kim, S. K., Choi, S. B., Bae, J., Kim, K. J., Kim, Y. J. and Paek, K. H. 2009. Pathogen-inducible CaUGT1 is involved in resistance response against TMV infection by controlling salicylic acid accumulation. FEBS Lett. 13:2315-2320.

Lee, H. I. and Raskin, I. 1999. Purification, cloning, and expression of a pathogen inducible UDP-glucose: salicylic acid glucosyltransferase from tobacco. J. Biol. Chem. 274:36637-36642.

Lim, E. K. and Bowles, D. J. 2004. A class of plant glycosyltransferases involved in cellular homeostasis. EMBO J. 23:29152922.

Liu, Y., Schiff, M. and Kumar, D. 2002. Virus-induced gene silencing in tomato. Plant J. 31:777-786.

Loake, G. and Grant, M. 2007. Salicylic acid in plant defence: the players and protagonists. Curr. Opin. Plant Biol. 10:466-472.

Ma, L., Liu, B., Gao, D., Pang, X., Lü, S., Yu, H., Wang, H., Yan, F., Li, Z., Li, Y. and Ye, H. 2007. Molecular cloning and overexpression of a novel UDP-glucosyltransferase elevating salidroside levels in Rhodiola sachalinensis. Plant Cell Rep. 26:989-999.

Mou, Z., Fan, W. and Dong, X. 2003. Inducers of plant systemic acquired resistance regulate NPR1 function through redox changes. Cell 113:935-944.

Navarro, L., Dunoyer, P., Jay, F., Arnold, B., Dharmasiri, N., Estelle, M., Voinnet, O. and Jones, J. D. G. 2006. A plant miRNA contributes to antibacterial resistance by repressing auxin signaling. Science 312:436-439.

O’Donnell, P. J., Schmelz, E. A., Moussatche, P., Lund, S. T., Jones, J. B. and Klee, H. J. 2003. Susceptible to intolerance-a range of hormonal actions in a susceptible Arabidopsis pathogen response. Plant J. 33:245-257.

Park, S. W., Kaimoyo, E., Kumar, D., Mosher, S. and Klessig, D. 2007. Methyl salicylate is a critical mobile signal for plant systemic acquired resistance. Science 318:113-116.

Quiel, J. A. and Bender, J. 2003. Glucose conjugation of anthranilate by Arabidopsis UGT74F2 glucosyltransferase is required for tryptophan mutant blue fluorescence. J. Biol. Chem. 278:6275-6281.

Radman, J. C., Haas, B. J., Tanimoto, G. and Town, C. D. 2004. Development and evaluation of an Arabidopsis whole genome Affymetrix probe array. Plant J. 38:545-561.

Ross, A. F. 1961. Localized acquired resistance to plant virus infection in hypersensitive hosts. Virology 14:329-339.

Ross, J., Li, Y., Lim, E. and Bowles, D. J. 2001. Higher plant glycosyltransferases. Genome Biol. 2:30041-30046.

Rossi, M., Goggin, F. L., Milligan, S. B., Kaloshian, I., Ullman, D. E. and Williamson, V. M. 1998. The nematode resistance gene $M i$ of tomato confers resistance against the potato aphid. Proc. Natl. Acad. Sci. USA 95:9750-9754.

Seki, M., Narusaka, M., Abe, H., Kasuga, M., Yamaguchi-Shinozaki, K., Carninci, P., Hayashizaki, Y. and Shinozaki, K. 2001. Monitoring the expression pattern of 1300 Arabidopsis genes under drought and cold stresses by using a full-length
cDNA microarray. Plant Cell 13:61-72.

Shulaev, V., Silverman, P. and Raskin, I. 1997. Airborne signaling by methyl salicylate in plant pathogen resistance. Nature 385:718-721.

Song, J. T. 2006. Induction of a salcyclic acid glucosyltransferase, AtSGT1, is an early disease response in Arabidopsis thaliana. Mol. Cells 22:233-238.

Spoel, S. H., Koornneef, A., Claessens, M. C., Korzelius, J. P., Van Pelt, J. A., Mueller, M. J., Buchala, A. J., Métraux, J., Brown, R., Kazan, K., Van Loon, L. C., Dong, X. and Pietersela, C. 2003. NPR1 modulates cross-talk between salicylate- and jasmonate-dependent defense pathways through a novel function in the cytosol. Plant Cell 15:760-770.

Spoel, S. H., Johnson, J. S. and Dong, X. 2007. Regulation of tradeoffs between plant defenses against pathogens with different lifestyles. Proc. Natl. Acad. Sci. USA 104:18842-18847.

Tada, Y., Spoel, S. H., Pajerowska-Mukhtar, K., Mou Z., Song, J. and Dong, X. 2008. Plant Immunity Requires Conformational Changes of NPR1 via S-Nitrosylation and Thioredoxins. Science 321:952-956.

The Arabidopsis Genome Initiative 2000. Analysis of the genome sequence of the flowering plant Arabidopsis thaliana. Nature 408:796-815.

Thilmony, R., Underwood, W. and He, S. Y. 2006. Genome-wide transcriptional analysis of the Arabidopsis thaliana interaction with the plant pathogen Pseudomonas syringae pv. tomato DC3000 and the human pathogen Escherichia coli O157:H7. Plant J. 46:34-53.

Tognetti, V., Van Aken, O., Morreel, K., Vandenbroucke, K., Van De Cotte, B., De Clercq, I., Chiwocha, S., Fenske, R., Prinsen, E., Boerjan, W., Genty, B., Stubbs, K., Inzé, D. and Van Breusegem, F. 2010. Perturbation of indole-3-butyric acid homeostasis by the UDP-glucosyltransferase UGT74E2 modulates Arabidopsis architecture and water stress tolerance. Plant Cell 22:2660-2679.

Vernooij, B., Friedrich, L., Morse, A., Reist, R., KolditzJawhar, R., Ward, E., Uknes, S., Kessmann, H. and Ryals, J. 1994. Salicylic acid is not the translocated signal responsible for inducing systemic acquired resistance but is required in signal transduction. Plant Cell 7:959-965.

Wang, R., Guegler, K., LaBrie, S. T. and Crawford, N. M. 2000. Genomic analysis of a nutrient response in Arabidopsis reveals diverse expression patterns and novel metabolic and potential regulatory genes induced by nitrate. Plant Cell 12:1491-1509.

Wang, D., Pajerowska-Mukhtar, K., Culler, A. H. and Dong, X. 2007. Salicylic acid inhibits pathogen growth in plants through repression of the auxin signaling pathway. Curr. Biol. 17:1784-1790.

Wildermuth, M. C., Dewdney, J., Wu, G. and Ausubel, F. M. 2001. Isochorismate synthase is required to synthesize salicylic acid for plant defence. Nature 414:562-565.

Zimmermann, P., Hirsch-Hoffmann, M., Hennig, L. and Gruissem, W. 2004. GENEVESTIGATOR Arabidopsis microarray database and analysis toolbox. Plant Physiol. 136:2621-2632. 